\title{
The persistence of ligature marks: towards a new protocol for victims of abuse and torture
}

\author{
L. Spagnoli • D. Mazzarelli • D. Porta • D. Gibelli • \\ M. Grandi • A. Kustermann • C. Cattaneo
}

Received: 13 April 2013 / Accepted: 27 August 2013 / Published online: 21 September 2013

(C) Springer-Verlag Berlin Heidelberg 2013

\begin{abstract}
One of the most frequently observed lesions in clinical forensic practice concerns the patterned abrasion on skin due to constriction by various types of ligature. Detection of ligature marks and their patterns may be fundamental for reconstructing events and supporting testimony of an aggression, sexual abuse, or maltreatment. But very little actually exists in literature concerning their detectability and how long they last. This study aims at evaluating the time of persistence and detectability of skin signs left by different types of ligatures in living persons: on the arms of three volunteers, eight different ligatures were applied; 123 tests were performed, with time of contact ranging between $1 \mathrm{~min}$ and $2 \mathrm{~h}$ and $45 \mathrm{~min}$. In addition, the persistence of the shape and pattern of the ligature was evaluated 15, 30, and $60 \mathrm{~min}$ after a 5 - and 15-min compression. Polyvinyl siloxane, applied by a gun dispenser, was used to perform a cast of the skin mark. The results show that the pattern was less distinguishable with the decrease of time of contact, going from $75 \%$ after 10 and $15 \mathrm{~min}$ of contact, to $45.8 \%$ after $1 \mathrm{~min}$. Above $15 \mathrm{~min}$, the specific pattern was always recognizable. In addition, a progressive decrease of the detectability of the pattern with time, respectively, up to 12.5
\end{abstract}

L. Spagnoli $\cdot$ D. Mazzarelli $\cdot$ D. Porta $\cdot$ D. Gibelli $\cdot$ M. Grandi $\cdot$

C. Cattaneo $(\bowtie)$

LABANOF, Laboratorio di Antropologia e Odontologia Forense, Sezione di Medicina Legale, Dipartimento di Scienze Biomediche per la Salute, Università degli Studi di Milano, V. Mangiagalli 37, Milan, Italy

e-mail: cristina.cattaneo@unimi.it

D. Gibelli · A. Kustermann • C. Cattaneo

SVSeD, Soccorso Violenza Sessuale e Domestica, Fondazione IRCCS Cà Granda, Ospedale Maggiore Policlinico di Milano, Milan, Italy and $37.5 \%$ in 5- and 15-min tests was observed. This study provides useful results for the assessment of patterned injuries in forensic pathology and clinical forensic medicine, both on dead and living persons: in addition, the use of silicone casts seems to be a reliable and cheap method for easily recording and preserving the morphological profile of skin lesions.

Keywords Forensic pathology $\cdot$ Clinical forensic medicine . Maltreatment · Sexual abuse · Blunt trauma $\cdot$ Ligature . Patterned lesion

\section{Introduction}

The assessment of skin lesions is important in forensic pathology, where injuries show a patterned shape; even more precise information may be available for the reconstruction of the tool and the weapon used on the skin. For example, some bruises and abrasions are patterned because of their shape and depict the outline, even the structure and other characteristics of the weapon or parts of the weapon [1]: in fact, if a tool with a patterned surface strikes the skin, the abrasion of the epidermis can reproduce the structure of the object $[2,3]$. This phenomenon may also cause the compression of the skin into the cavities of the pattern, with consequent capillary damage leading to an intradermal bruise.

One type of patterned lesion observed in forensic practice deals with signs of ligatures: in autopsies, the analysis of the patterned groove on the neck of a body can aid in the study of the type of hanging or strangulation $[4,5]$. In the field of clinical forensic medicine, finding signs of ligatures on the body (e.g., wrists) may help in confirming the version 
Table 1 Contact time and number of tests performed on subject A, B, C for Part I

\begin{tabular}{|c|c|c|c|c|c|}
\hline \multicolumn{2}{|l|}{ Subject A } & \multicolumn{2}{|l|}{ Subject B } & \multicolumn{2}{|l|}{ Subject C } \\
\hline Contact time & Number of tests & Contact time & Number of tests & Contact time & Number of tests \\
\hline $1 \mathrm{~min}$ & 8 & $1 \mathrm{~min}$ & 8 & $1 \mathrm{~min}$ & 8 \\
\hline $5 \mathrm{~min}$ & 8 & $5 \mathrm{~min}$ & 8 & $5 \mathrm{~min}$ & 8 \\
\hline $10 \mathrm{~min}$ & 8 & $10 \mathrm{~min}$ & 8 & $10 \mathrm{~min}$ & 8 \\
\hline $15 \mathrm{~min}$ & 8 & $15 \mathrm{~min}$ & 11 & $15 \mathrm{~min}$ & 9 \\
\hline $1 \mathrm{~h} 15 \mathrm{~min}$ & 1 & $20 \mathrm{~min}$ & 1 & $20 \mathrm{~min}$ & 2 \\
\hline $1 \mathrm{~h} 20 \mathrm{~min}$ & 4 & $25 \mathrm{~min}$ & 1 & $25 \mathrm{~min}$ & 1 \\
\hline $1 \mathrm{~h} 30 \mathrm{~min}$ & 2 & $30 \mathrm{~min}$ & 3 & $30 \mathrm{~min}$ & 3 \\
\hline $2 \mathrm{~h} 45 \mathrm{~min}$ & 1 & & & $45 \mathrm{~min}$ & 1 \\
\hline Total & 40 & Total & 40 & Total & 40 \\
\hline
\end{tabular}

provided by the victim, for example, in cases of sexual abuse and in child abuse, where such injuries are often reported, and a careful analysis of the skin is needed in order to clarify the diagnosis [6] but also in cases of torture, where a prolonged application of tight ligatures may leave a linear zone extending circularly around limbs [7].

Among patterned lesions, signs of ligatures are relevant; however, very few studies are available concerning how to preserve them. Sharma et al. for example focused on the analysis of the pattern from a ligature mark, but only on photographs, and was able to identify ligature material in $17.58 \%$ of cases, whereas no sign of the pattern of a ligature was observed in $71.43 \%$ of cases [8]. Most of the studies concerning this topic usually deal with case reports [9]. Very few indications are available on ligature signs, their modifications with time, and the correct manner for assessing and reproducing such lesions in order to improve the quantity of information which may be drawn [10].

This study aims at partly filling the gap by evaluating the time of persistence and detectability of skin signs left by different types of ligatures in living persons in order to provide information for the assessment of such lesions in forensic practice.

\section{Materials and methods}

The experimental project included eight different ligature types and in detail: the first was a white and gray rope for rolling shutters (20.2 mm wide and $1.8 \mathrm{~mm}$ thick), with a pattern made of 1-mm-sided squares; the second one a red
Fig. 1 Ligature no. 3, applied for $15 \mathrm{~min}$, immediately after its removal: a skin groove, $\mathbf{b}$ cast, c cast imprint in ink, and d comparison between the imprint and the applied ligature a

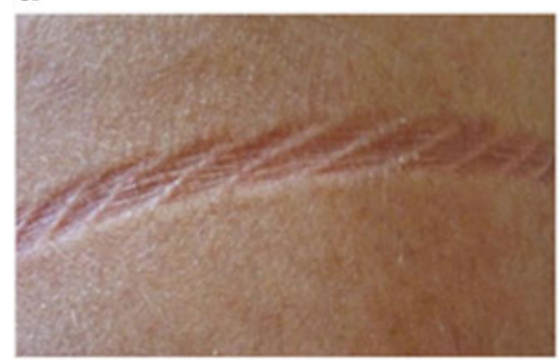

b

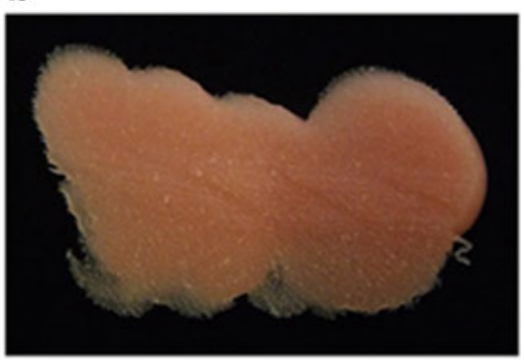

c

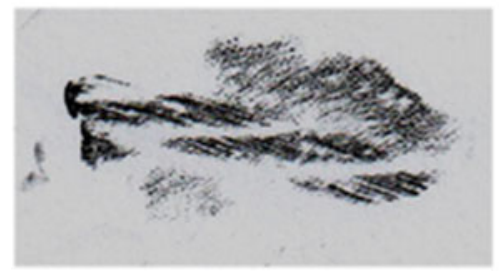

d

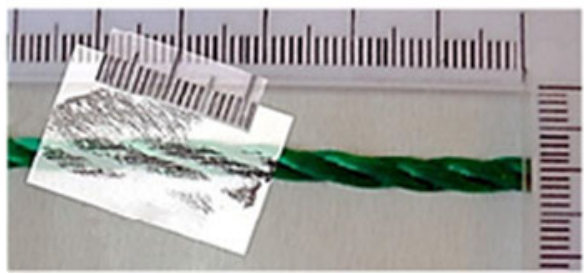




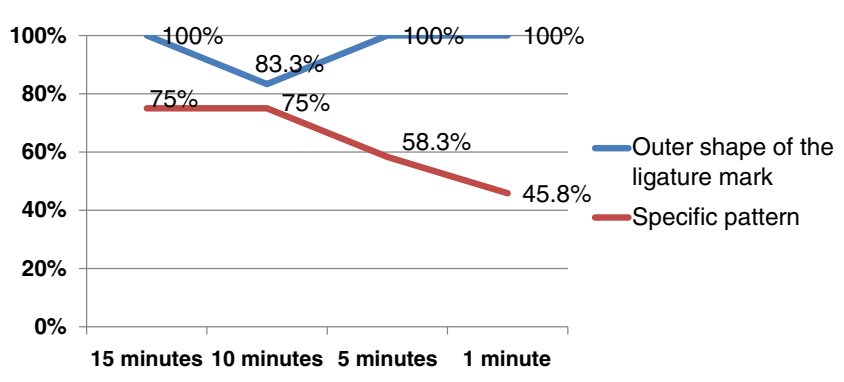

Graph 1 Detectability of shape and pattern of lesion with time of contact of the ligature on the skin

cotton string (4.2 mm wide and $1.2 \mathrm{~mm}$ thick) with a crisscrossed oblique pattern; the third one was a green synthetic rope (2.9 $\mathrm{mm}$ in diameter) composed of two smaller cords of the same diameter intertwined among each other; the fourth one an orange-yellow silver synthetic cord (2.1 $\mathrm{mm}$ in diameter) similar to the third but with three smaller cords intertwined; the fifth one was a beige hemp simple rope (diameter ranging between 3.2 and $4.5 \mathrm{~mm}$ ); the sixth was one a white synthetic simple rope (3.2 $\mathrm{mm}$ in diameter); the seventh one a gray electric cable (3.3 $\mathrm{mm}$ in diameter) with a smooth surface; and the eighth one was a belt-in brown leather with a smooth surface (4.4 mm wide and $2.5 \mathrm{~mm}$ thick). All the tests were performed on three volunteers:

- Subject A: 25 years old, $160 \mathrm{~cm}$ high, weighing $55 \mathrm{~kg}$ (BMI, 21.4).

- $\quad$ Subject B: 27 years old, $164 \mathrm{~cm}$ high, weighing $54 \mathrm{~kg}$ (BMI, 20).

- $\quad$ Subject C: 28 years old, $182 \mathrm{~cm}$ high, weighing $78 \mathrm{~kg}$ (BMI, 23.5).

Subject A was also used as the negative control for the appearance of uncompressed skin on a cast; in fact, a cast was performed on the skin of subject A which had not been compressed in order to confirm that without a previous ligature, no specific marks or lesions appeared. Two further tests were performed on much older individuals: subject D (60 years old; BMI, 30) and subject E (48 years old; BMI, 22 ), only without compression, simply to verify if the skin of aged people, more lax and wrinkled, presents peculiarities that may mimic a pattern. D and E were not subjected to further study.

To minimize the differences between the various tests, each test was always performed by the same operator, who wrapped the ligature only once around the arm always in the middle third of the arm of each subject, and tied a knot, always with the same strength. Of course, it is impossible to quantify the amount of energy applied, but the knot was tightened in all cases up to the point where it was not painful but uncomfortable.

\section{Part I}

The ligature was tied around the arm of a volunteer. The volunteer kept the ligature on his arm for a set time ranging between $1 \mathrm{~min}$ and $2 \mathrm{~h}$ and $45 \mathrm{~min}$. First of all, 20 tests were performed with a contact time ranging between $20 \mathrm{~min}$ and $2 \mathrm{~h}$ and $45 \mathrm{~min}$; in detail, a test was performed at 45, 75, and $165 \mathrm{~min}$, two tests at 25 and $90 \mathrm{~min}$, three tests at $20 \mathrm{~min}$, four tests at $80 \mathrm{~min}$, and six tests at $30 \mathrm{~min}$; then, 100 tests focused on a shorter contact time ranging between 1 and $15 \mathrm{~min}$ (24 tests at 1,5 , and $10 \mathrm{~min}$ and 28 at $15 \mathrm{~min}$ ). A total of 120 tests were performed (Table 1). As previously mentioned, subject A was the true negative control, subjects D and E were only a test for the effect of age on uncompressed skin.

After the ligature was removed, a picture of the ligature mark was immediately taken; in addition, a silicone impression of the ligature mark was performed with polyvinyl silox-
Fig. 2 Ligature no. 6, applied for $15 \mathrm{~min}$, after its removal: a skin groove, $\mathbf{b}$ cast, $\mathbf{c}$ cast imprint in ink, and $\mathbf{d}$ comparison between the imprint and the applied ligature a

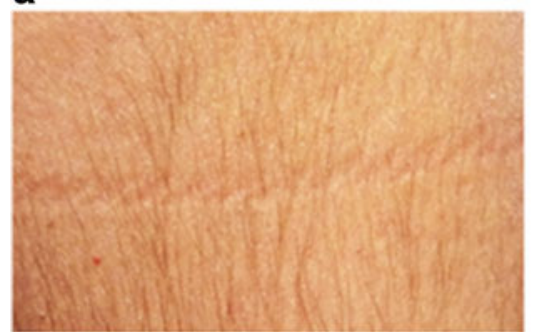

b

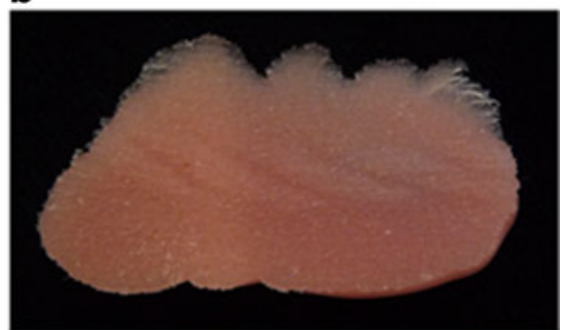

c

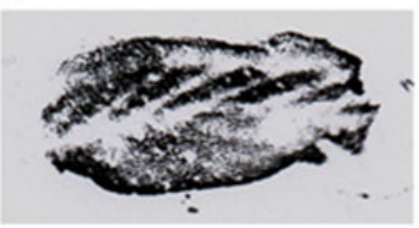

d

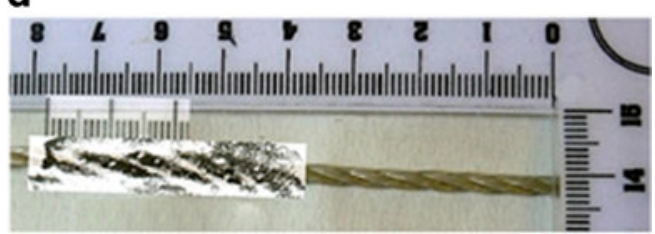


Fig. 3 Ligature no. 8, applied for $15 \mathrm{~min}, 30 \mathrm{~min}$ after its removal: a) skin groove, b: cast; c: cast imprint in ink; d: comparison between the imprint and the applied ligature a

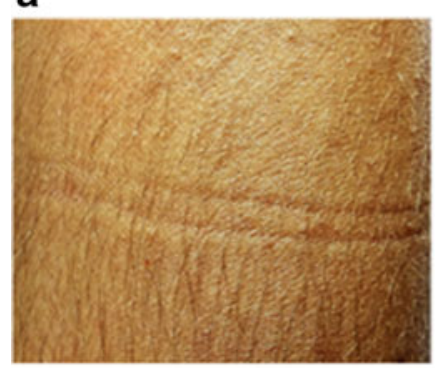

C

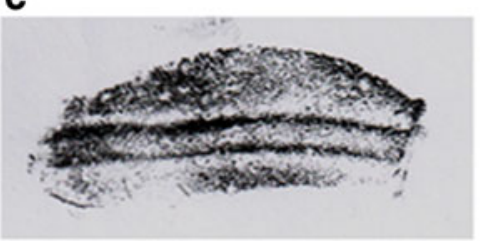

b

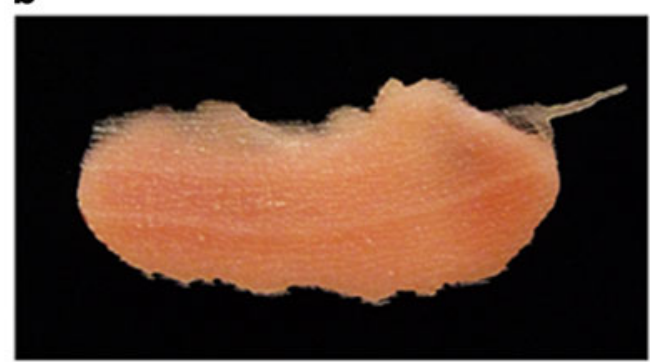

d

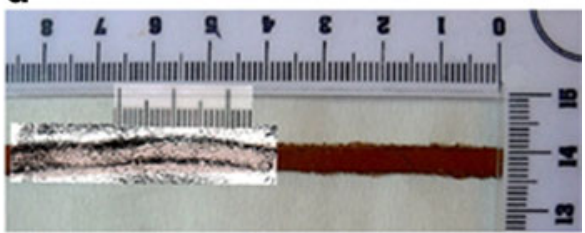

ane, applied onto the skin, covering an area of skin of $4 \mathrm{~cm}^{2}$, and with a thickness of at least $0.5 \mathrm{~cm}$, by using a gun dispenser immediately after the removal of the ligature. The polyvinyl siloxane was characterized by a working time of $1 \mathrm{~min}$, a setting time of $10 \mathrm{~min}$, a hardness of 70 shore $\mathrm{A}$, and a detail reproduction of $2 \mu$.

The silicone impression was then highlighted with ink which was applied with a fingerprint roller and transferred onto a white sheet of paper. In this way, a ligature mark imprint was obtained (Fig. 1). The mark was then evaluated according to the detectability of two parameters: the general outline of the ligature (defined as shape) and the inner pattern, given by the irregularity of the surface of the ligature.
Part II

In the second part of the study, the aim was to estimate how long it took the pattern on the skin to change/disappear in time, once the ligature was removed.

The eight different ligatures were tied for $5 \mathrm{~min}$ onto the arm of subject A; after removing them, a silicone cast of every ligature mark was performed at different times and in detail after 15, 30 and $60 \mathrm{~min}$. The same procedure was applied to signs left by the eight ligatures applied for $15 \mathrm{~min}$ : casts were performed after 15,30 , and $60 \mathrm{~min}$.

In this part of the study, the main steps were conducted as in Part I: the eight different ligatures, the quality and quantity of
Fig. 4 Ligature no. 2, applied for $5 \mathrm{~min}, 60 \mathrm{~min}$ after its removal: a skin groove, $\mathbf{b}$ cast, $\mathbf{c}$ cast imprint in ink, and $\mathbf{d}$ : comparison between the imprint and the applied ligature

\section{a}

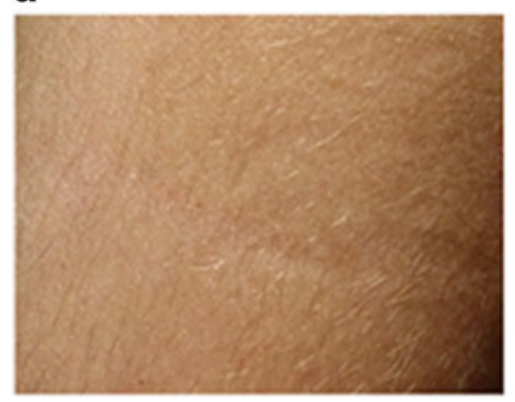

C

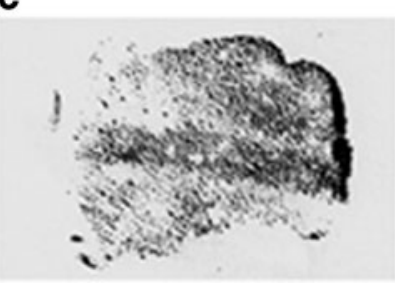

d b
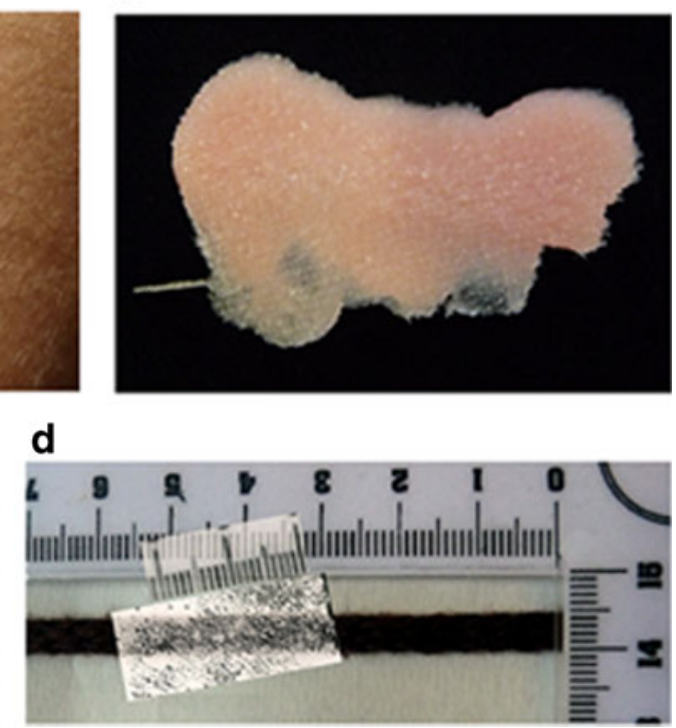
polyvinyl siloxane, and the operator that performed the tests were the same as in Part I.

In total, 48 trials were performed, with controls as for Part I (photo, silicone cast, ink imprint). The mark was then evaluated as for Part I.

\section{Results}

Part I

The analysis of the signs showed that in tests with a prolonged contact, a mark was always detectable in all three volunteers; the specific pattern of the ligature was also recognizable in $75 \%$ of cases.

When contact time was shortened between 1 and $15 \mathrm{~min}$, the specific pattern of the ligature mark was recognizable in $75 \%$ of cases after 10 and $15 \mathrm{~min}$ of contact, whereas the percentage decreased to 58 after $5 \mathrm{~min}$ and to only $46 \%$ after 1 min (Graph 1) (Figs. 1, 2, 3 and 4).

\section{Part II}

The modification of the shape and pattern of the lesion with time once the ligature was removed was evaluated as well: both the tests performed after a 5 - and 15-min contact between the ligature, and the skin showed a progressive decrease of the detectability of the pattern with time (Graphs 2 and 3); in detail, the pattern became less visible with time. After $60 \mathrm{~min}$, the ligature profile was recognizable only in 12.5 and $37.5 \%$ of cases, respectively, in 5 and $15 \mathrm{~min}$ tests. On average, the pattern was always less detectable after $5 \mathrm{~min}$ of contact between the ligature and the skin than after $15 \mathrm{~min}$. For what concerns the signs produced after a 15-min contact, the pattern of the ligature could no longer be verified after $90 \mathrm{~min}$. On the other hand, the shape of the ligature was almost always detectable in both groups (Fig. 5).

The negative control on uncompressed skin of subject A showed no peculiar pattern. The uncompressed skin tests on older individuals seemed to show no significantly different behavior with respect to young skin.

\section{Discussion}

In literature, no indication is given concerning the mode of production of patterned lesions, how long they persist, although they have a relevant importance in the forensic practice since they are the most informative signs which may be found during an autopsy, or a clinical examination of a victim of maltreatment or sexual abuse. This study aimed first at verifying how long the contact between the ligature and the

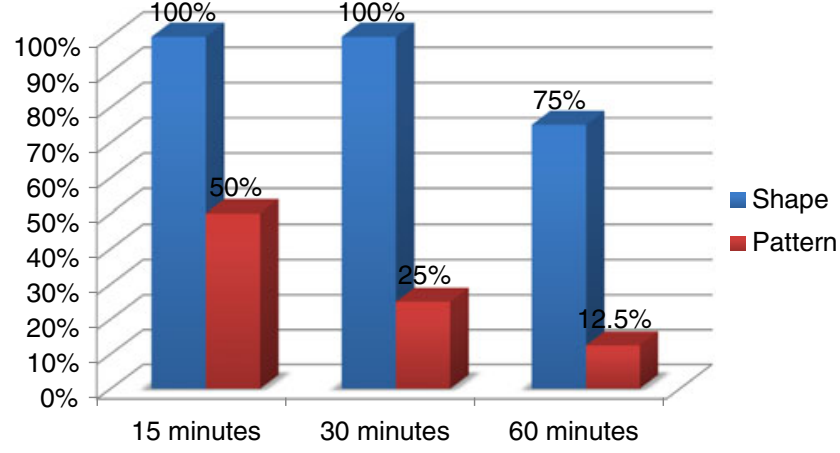

Graph 2 Detectability of shape and pattern of lesion after a 5-min contact between the ligature and the skin (i.e., 15, 30, and 60 min after the ligature has been removed)

skin should last in order to give a detectable image of the shape and pattern of the tool; in addition, the study focused on how long the signs last once the ligature has been removed. The results show that although the general shape of the ligature seems to be independent up to a certain extent of the time of contact or at least more durable in time, the same is not valid for the pattern of the lesions, which becomes sensibly less and less visible with the decrease of the contact time.

The results of the 15 min test series were extremely interesting because all imprints were evident, well detectable, and comparable to the corresponding tools. At $10 \mathrm{~min}$, the new imprints were still precise and visible, whereas after a $5 \mathrm{~min}$ contact, the detectability of the pattern strongly decreased, and after $1 \mathrm{~min}$ of compression of the ligature on the skin in most cases, it was no longer visible. These results show that although the shape is almost always visible, even after a brief contact, the pattern is more dependent on the time of compression. In comparison with the tests performed after a longer contact with the skin (above the $15 \mathrm{~min}$ threshold), the signs are less clear.

The last part of this study focused on the modification of the lesion with time; the results show that with a compression of $5 \mathrm{~min}$, the pattern was still detectable after $15 \mathrm{~min}$ in $50 \%$ of cases: interestingly, only in four cases the pattern was no

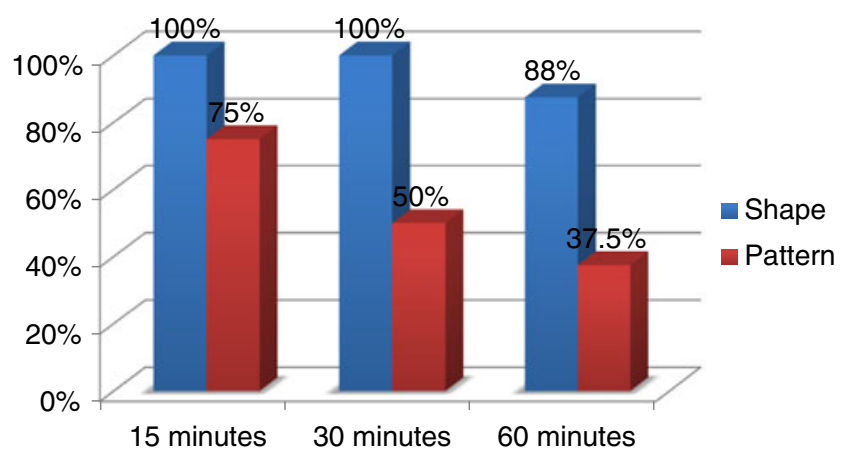

Graph 3 Detectability of shape and pattern of lesion after a 15-min contact between the ligature and the skin (i.e., 15, 30, and 60 min after the ligature has been removed) 
Fig. 5 Ligature no. 6, applied for $15 \mathrm{~min}$ and its impression: a immediately after its removal, $\mathbf{b}$ $15 \mathrm{~min}$ after its removal, c $30 \mathrm{~min}$ after its removal, and d $60 \mathrm{~min}$ after its removal a
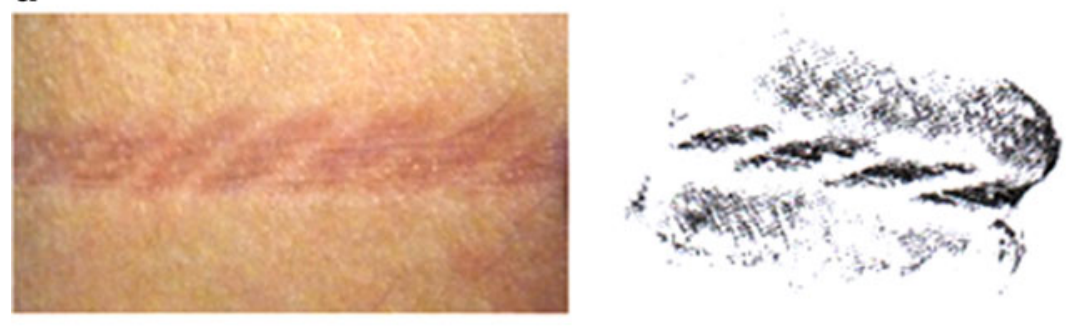

b
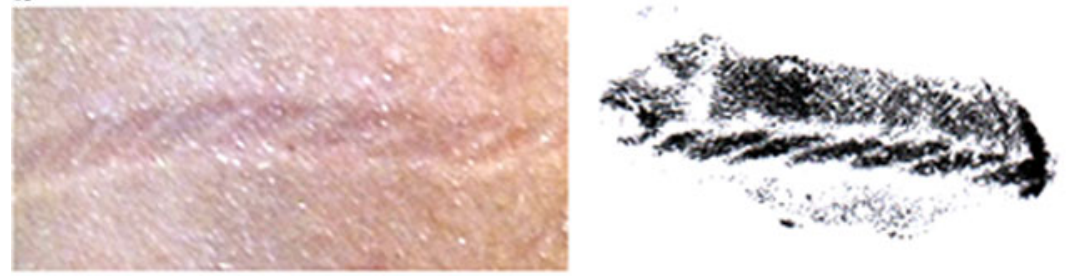

c

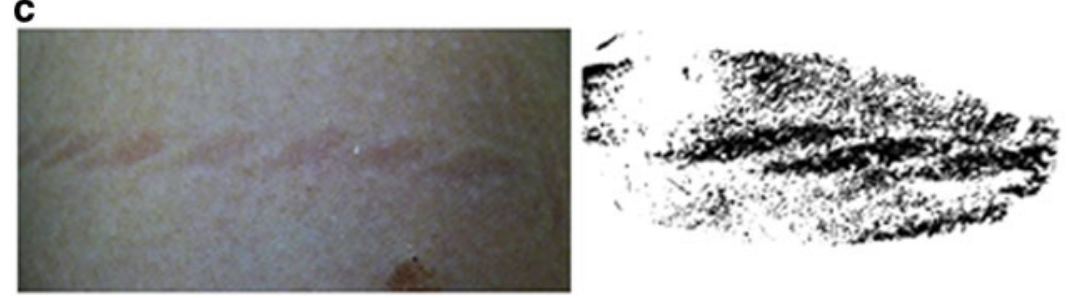

d
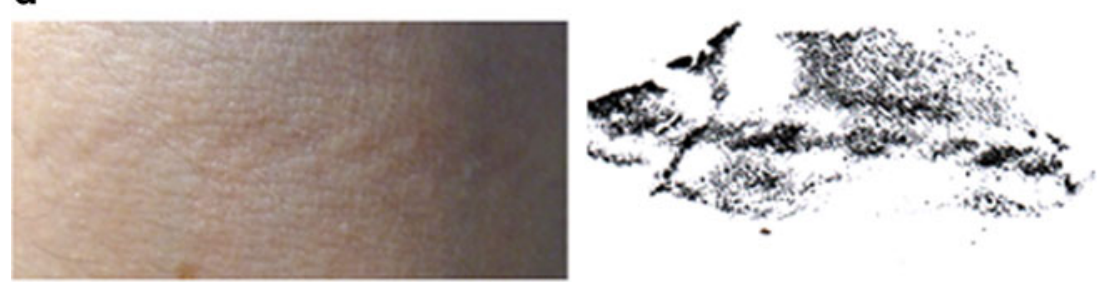

longer visible, and in two of them, the lesion was produced by a ligature with a less defined structure. After $30 \mathrm{~min}$, there was a decrease in detectability of the pattern, whereas the shape of the lesion was still detectable. After 60 min only in $12.5 \%$ of cases, the pattern was still visible. From a practical point of view, 60-90 $\mathrm{min}$ (at least with the material used in this experiment) is an important time limit because victims of abuse may reach emergency services within $1 \mathrm{~h} / 1.5 \mathrm{~h}$ from events, although it frequently happens that they arrive later. Nonetheless, the present study does demonstrate that with pressure on the volunteers which was not painful and definitely not violent for obvious reasons, signs of a ligature mark may last up to over $1 \mathrm{~h}$ when constriction lasted $15 \mathrm{~min}$; if we therefore imagine real cases where constriction is more violent and possibly for a longer time, it does seem worthwhile in cases where the victim has been tied to look for such signs and record them as best as possible.

Thus, searching for signs of ligature and trying to highlight and enhance even minimal signs on the skin may well be worthwhile, especially in dedicated emergency centers. In fact, after $1 \mathrm{~h}$ from removal of the ligature, the imprint was still detectable, as well as the shape; in the tests where compression lasted $15 \mathrm{~min}$, the shape of the ligature was still visible $90 \mathrm{~min}$ from its removal.

Furthermore, the method proposed here seems to act as a useful enhancer of such signs. Performing a silicone cast which is subsequently inked seems reliable for recording and preserving the pattern of the lesion; in addition, it is cheap and easy to perform; therefore, even if this is a preliminary study and more tests need to be performed to improve the technique and to analyze all variables, one can envisage in the future including this procedure in standard protocols of treatment of skin lesions in victims of assault, together with the photographic documentation and other samples.

Of course, variables are too many to say that the present study proves that ligature marks always persist in this fashion and can still be seen after a specific period of time - amount of pressure, ligature type, skin characteristics, body mass index, etc. may all create enormous variations in single cases. However, the study stresses two important points: such marks can remain for quite a long time (especially considering that in real cases, violence is possibly greater therefore time of 
constriction and pressure also) and it is therefore worth looking for them; the performance of casts or molds with consequent inking may help enhance a pattern difficult to be seen by the naked eye or on a photograph.

\section{References}

1. Spitz WU, Spitz DJ (2006) Medicolegal investigation of death. Charles C Thomas, Springfield

2. Saukko P, Knight B (2005) Forensic pathology, 3rd edn. Arnold, London

3. Langlois NEI (2009) A patterned abrasion on the neck of an infant: inflicted injury or not? Forensic Sci Med Pathol 5:324-325
4. Jayaprakash S, Sreekumari K (2012) Pattern of injuries to neck structures in hanging - an autopsy study. Am J Forensic Med Pathol 33(4):395-399

5. Mohanty MK, Rastogi P, Kumar GP, Kumar V, Manipady S (2003) Periligature injuries in hanging. J Clin Forensic Med 10:255-258

6. Pau-Charles I, Darwich-Soliva E, Grimalt R (2012) Signos cutáneos del maltrato infantil. Actas Dermosifiliogr 3:94-99

7. Danielsen L, Rasmussen OV (2006) Dermatological findings after alleged torture. Torture 16(2):108-127

8. Sharma BR, Harish D, Singh P (2005) Ligature mark on neck: how informative? JIAFM 27:1-15

9. Milkovich S, Owens J, Stool D, Chen X (2005) Accidental childhood strangulation by human. Int J Pediatr Otorhinolaryngol 69:16211628

10. Di Maio VJ, Di Maio D (2001) Asphyxia. In: Di Maio VJ, Di Maio D (eds) Forensic Pathology, 2nd edn. CRC Press, Boca Raton, pp 230-275 